\title{
Vulnerabilities and opportunities in scientific research
}

Citation for published version (APA):

Akrong, L. (2019). Vulnerabilities and opportunities in scientific research: participant perspectives, and the contextualization of clinical trial conduct and involvement in sub-Saharan African settings. [Doctoral Thesis, Maastricht University]. ProefschriftMaken Maastricht. https://doi.org/10.26481/dis.20190702la

Document status and date:

Published: 01/01/2019

DOI:

10.26481/dis.20190702la

Document Version:

Publisher's PDF, also known as Version of record

\section{Please check the document version of this publication:}

- A submitted manuscript is the version of the article upon submission and before peer-review. There can be important differences between the submitted version and the official published version of record.

People interested in the research are advised to contact the author for the final version of the publication, or visit the DOI to the publisher's website.

- The final author version and the galley proof are versions of the publication after peer review.

- The final published version features the final layout of the paper including the volume, issue and page numbers.

Link to publication

\footnotetext{
General rights rights.

- You may freely distribute the URL identifying the publication in the public portal. please follow below link for the End User Agreement:

www.umlib.nl/taverne-license

Take down policy

If you believe that this document breaches copyright please contact us at:

repository@maastrichtuniversity.nl

providing details and we will investigate your claim.
}

Copyright and moral rights for the publications made accessible in the public portal are retained by the authors and/or other copyright owners and it is a condition of accessing publications that users recognise and abide by the legal requirements associated with these

- Users may download and print one copy of any publication from the public portal for the purpose of private study or research.

- You may not further distribute the material or use it for any profit-making activity or commercial gain

If the publication is distributed under the terms of Article $25 \mathrm{fa}$ of the Dutch Copyright Act, indicated by the "Taverne" license above, 


\section{English summary}

The main aim of this study, as introduced in Chapter 1 was to understand how participants engaged and approached the norms associated with involvement in clinical research. The participation of people in biomedical research, particularly from lower-resourced countries, has been associated with concern regarding risk, vulnerability and exploitation. While they remain valid concerns in general when it comes to human involvement in research, a lack of understanding in how participants, in this case, from sub-Saharan African countries, approach and deal with these issues prior to, and in the course or participation hinders our ability to further develop more mutually beneficial governance and participation frameworks. With a large amount of fatalities connected to communicable and noncommunicable diseases across the African continent, trials can provide an opportunity for the development of beneficial interventions to combat this problem. However, as the number of trials increase, so too does the number of trial participants needed to satisfy international regulatory demands. Understanding how participants engage and make sense of research and being a trial participant is of great importance if the goal is to improve research practices and to make research participation more beneficial, not only for research, but for the research participant.

This chapter lays out several narratives through which participation is often discussed. It gives context to the narrative of the vulnerable 'participant' in research and concerns for their safety and overall well-being. It provides a broad introduction into early cases of abuse, namely, the Tuskegee syphilis study and the Nazi prisoner experiments, that to this day are called upon to stress the need for protection of humans involved in research. Vulnerability and protection go hand in hand, yet the question of who's shoulders responsibility rests upon, who is owed what, and to what extent, is a matter of ongoing debate. From research ethics committee members (RECs) to Institutional Review Boards (IRBs), to the investigators themselves, there are several actors to consider here; not the least of which is the participant and how their perceptions of research and involvement factor into decision-making and the construction of meaning within trial research. In line with this thought and against the background of the globalization of trial conduct and participation, I start to unpack how perceptions and constructed meanings can come to frame vulnerabilities and/or opportunities in lower-resourced settings, while mainly focusing on Ghana and Tanzania. Underlying these framings are a range of issues including community citizenship, healthcare access, health consultation, education, risks, illiteracy, poverty and disease burden. While thinking about the potential for vulnerabilities to be created or opportunities provided, the chapter notes that it is important to reflect on, from who's perspective are these framings being given, and how can they help in terms of making trials safe, yet beneficial to all involved. With this in mind, the main question I explore in this book through qualitative, empirical research, is how can the articulated perspectives and opinions of African trial participants, emerging at the intersection of international clinical research and local trial engagement, contribute to the development of more sustainable and mutually beneficial research framework(s), policies and healthcare practices in lower-resourced settings?

After setting the background in the in the previous chapter, Chapter $\mathbf{2}$ is used to give context to the idea that participation $\mathrm{s}$ in lower-resourced settings is complicated in nature and the perceptions of research and participation as demonstrated by participants should not necessarily be dismissed as a lack of understanding or ignorance of science. It delves into the therapeutic misconception (TM) as it is applied to trial participants. As the research question I have posed is interested in the perspectives and opinions of African trial participants and the development of beneficial frameworks, this chapter explores how research ethics and policy development has been influenced by distinctions made between clinical research and therapeutic treatment. In the case of lower-resourced country participants, it is not uncommon for there to be scepticism as to whether or not there is confusion as to the suggested purpose 
of research - to produce generalizable knowledge rather than individual benefit - and their place within this process, what is referred to as TM. The chapter traces the development of TM and how documents such as the Belmont Report emphasize the need to have a clear distinction established between research and care and the problematic nature of conflation between the two activities. Obtaining informed consent (IC) is believed to be a core pillar of research ethics, and the TM is argued to threaten its validity. Participants should surely know what they are getting into when involved in clinical trials. However, the application of TM has been

it would seem clear to everyone that participants should be fully aware of what they are getting into, when trying to determine when TM is present and whether it is applies is not clear. There remains much debate about the distinction between research and care. The term TM itself, has evolved over the years. Originally it took on a narrower definition and referred to the failure to understand the restrictions placed on medical treatment by the research protocol. However other the years it has expanded beyond confusion regarding research protocols in a particular procedure to include general misperceptions about clinical research. As a result, TM has become a type of umbrella term covering anything from broad benefit expectation, to therapeutic mis-estimation of risks and/or benefits to therapeutic optimism (the benefit of participation for the individual). Through this chapter, it is shown that there is need to exercise caution in applying the TM term, particularly when considering the complex nature in which participation in lower-resource settings takes place.

Chapters four through six in this book, represent the core findings of my research. In these chapters I present description and analysis of emergent themes and their relation to the traditional and alternative perspectives on various research norms. Against the background of a lack of healthcare infrastructure, combined with the widespread problem of communicable and non-communicable diseases negatively impacting the health and well-being of local populations, chapter 3 explores the characteristics of participants involved in research and their motivations for trial engagement. I explore the context in which Ghanaian trial participants engage in research and what influences are at play. Generally, reasons for participation are said to be either altruistic or for personal gain. Literature has suggested that participation in lower-resourced settings can often be attributed to a lack of options or the desire for monetary compensation. In my study I show how in these settings such assumptions do not explain what is happening on the ground. I present a more complex view of the trial participant, one who's motivations are multi-layered and are composed of both collectivist and individualistic dimensions rooted. These dimensions are not distinct, but rather fluid categorizations that shift, influenced by an understanding that a person is at the same time an individual and part of a wider community. As such terms such as I WE YOU ME are interchangeable and reflect a broader understanding of not only who the trial participant is, but also influences how they develop ideas about what the responsibilities of actors and community members are. From my findings, I show that while participants are interested in contributing to the wider society, it is not necessarily that it comes from a wholly altruistic place, as they describe a situation where collective intentions are coupled with individual benefit. Furthermore, in this integration of personal and society motives for participation I suggest the need to take the complex nature of the trial participant that understands that there is trade off between the risk innate in research and the potential individual/societal benefits that clinical trial participation brings.

Chapter 4 illustrates the developing relationships, evolving roles and expectations that occur within trials. The results I present show that over the course of a trial, Ghanaian and South African research participants, along with investigators, reshaped the dynamic between them. Rather than adhere to the traditional model of investigator-participant dynamics, participants engaged in interactions that altered the distinction between the role of the investigator and themselves. The results I describe here are important when considering the notion that clinical research should be thought of as distinct from therapeutic care. What I show in this chapter is that the context in which the trials were taking place, a low resource setting where contributing to community was an important influence, created an 
environment where roles, expectations and ideas about obligation and responsibility were negotiable rather than fixed terms. In a place where resources needed to be maximized, participants pushed for inclusion and felt themselves equal contributors to the research process. My work shows how the trial was a place for (re)negotiation, participants actively expressed their desires and expectations for what they viewed the purpose of the trial to be, what would happen with the results at the end of the trial, and how the trial could be used to generate more benefit for themselves and the wider community. Importantly, I show that participants saw themselves as equal contributors, and that accountability was important. Therefore, they were quite explicit in articulating under what circumstances they would feel as if their expectations were not met, or that their concerns were not taken seriously, at which point participants demonstrated their willingness to pull out of the trial, or not participant in future trials.

Chapter 5 looks at how participants in Ghana and Tanzania approached risk-benefit assessment. Traditionally risk and benefits are determined before a trial begins. Investigators, Research Ethics Committees (RECs) and Institutional Review Boards (IRBs), discuss and established what harms a trial may bring and what benefits are to be expected from conducting the research. When considering participation in a trial, a participant is able to review the proposed risks and benefits and then decide for themselves if they wish to participate. My work shows that in addition to going through this traditional approach to risk-benefit assessment, where participants are presented with the direct risks and in/direct benefits, and asked to consider whether the direct risks are in acceptable proportion to the direct benefits, before deciding whether joining the trial is right for them. With my work, I highlight how there are additional considerations coming into play. The chapter looks at how indirect benefits and risks are seen by Ghanaian and Tanzanian participants as not only being a matter of potential direct risks, but also what I describe as indirect risks that they would incur had they not participated in the trial. This differs from the traditional approach that is not inclined to include indirect benefits and direct risks, as it would be seen as a slippery slope towards TM. Using this alternative approach in combination with the traditional approach, participants were able to ensure that the trial itself was determined to be safe to participate in according to the traditional approach to risk-benefit assessment, and at the same time, provided additional indirect benefits that made it more beneficial for those contributing to the trial.

Chapter 6, analysed how trust factored into trial participation and the mechanisms through which it was developed, established and substantiated. My work shows that trust is central to developing relationships over the course of the trial, engaging in measured risk-benefit assessment and supporting motivations behind trial involvement. Trust is necessary for clinical research to work, it considered to be at the centre of trial conduct and has implications for every aspect of trial work and involvement. It can foster to a good working relationship or it can lead to increased chances of harm if naïve trust is given and not questioned. Research regulation development has been one way that we have tried to increase public trust in science. However, dependency on regulation alone is not enough, and when unchecked, creates opportunities for exploitation. On the other hand, as I show in this chapter, when developed through tested mechanisms, trust can be used to increase accountability, professionalism and safety in lower-resourced areas where oversight is not always as strong in compared to research done in higher resourced countries. IN my work I show how participants use familiarity with sources, personal networks, individual and institutional reputation, and substantiation over the course of participation to validate trust. In doing so I provide insight into how this is used to diminish the possibility of exploitation that can occur with naïve trust.

In the final chapter, Chapter 7, I conclude with a general discussion on the main findings of the book. I provide reflection on the core chapters. I link the harvest of the core empirical chapters explaining more in detail how the motivations for participation are contextualized and supported by a fluid understanding and relationship between the individual and their connection to the wider community. I then take this idea and how relationships develop in research, both in the Ghanaian context 
and the South African context, using data from a complimentary study. I also show how these relationships help to influence how trials are ultimately seen and engaged with. Understanding the importance of relationships, I then explain how this serves to reinforce risk-benefit assessment strategies based on beliefs they developed through relationships and shaped expectations, as well as how trust factors into this process.

Further in this chapter I reflect on two themes that were prevalent throughout the course of this book: contextualization and vulnerability. Research done in lower-resourced countries have drawn special attention due to the environment in which research takes place, and the population that is involved in the research. In this section I reflect on how context is suggested to impact research in literature versus how it is perceived by participants in these settings. I also highlight how it is the context itself that provides the opportunity, and perhaps necessity, to approach trial participation from both a traditional and alternative angle. Overall my works shows that local perspectives have much to offer, and that contrary to what may be believed, it should not just be plainly assumed that participants are vulnerable or do not have the ability to engage in thoughtful consideration in regards to their own participation and safety. While there is no simple solution, participant perspectives demonstrate insight which should be taken seriously by actors such as RECs and IRBs in their efforts to develop more sustainable and mutually beneficial research frameworks, particularly when it comes to dealing with those from lowerresourced settings. 